\title{
Synthetic aperture technique applied to a multi-beam echo sounder
}

\author{
Akira Asada ${ }^{1}$ and Tetsuichiro Yabuki ${ }^{2}$ \\ ${ }^{1}$ Institute of Industrial Science, University of Tokyo, 7-22-1 Roppongi, Minato-ku, Tokyo 106-8558, Japan \\ ${ }^{2}$ Japan Hydrographic Department, 5-3-1 Tsukiji, Chuo-ku, Tokyo 104-0445, Japan
}

(Received July 1, 1999; Revised June 21, 2000; Accepted June 21, 2000)

\begin{abstract}
We are developing a synthetic aperture technique using a Sea Beam 2000 multi-beam echo sounder to observe subsea crustal movements for earthquake studies. Augmented by the Kinematic GPS and a motion sensor, the synthetic aperture technique was successfully applied to the Sea Beam 2000 with a $12 \mathrm{kHz}$ frequency acoustic signal. The 4.3-meter long projector produces a transmission fan beam in alongtrack beamwidth of 2 degrees, but a synthesis of the data achieved about $37 \mathrm{~m}$ aperture length, equivalent to a 0.3 degrees alongtrack beamwidth. Bathymetry measurements at the water depth of $900 \mathrm{~m}$ obtained through the synthetic aperture processing show considerable improvement of the signal-to-noise ratio and reveal detailed features of the seafloor.
\end{abstract}

\section{Introduction}

We are developing new technology for the observation of subsea crustal movements related to large earthquakes. These earthquakes have occurred repeatedly along the subduction zones around Japan, for example, along the Nankai Trough. We expect that there is significant pre-, co- and post-seismic deformation at the ocean bottom, but the deformation is difficult to observe because of the presence of seawater. The detection of such deformation will advance our understanding of the mechanisms of large earthquake.

On land, mapping of fault distribution is now carried out efficiently by the synthetic aperture radar (SAR) from satellites or airplanes. Furthermore, crustal deformation caused by faulting is estimated using the SAR interferometry (Massonnet et al., 1993). A synthetic aperture technique using a swath echo sounder with two row transducer (Stubbs et al., 1974) was designed more than ten years ago (Spiess and Anderson, 1983), but it has scarcely been used to provide high-resolution bathymetry.

In this paper, we report our trials to apply the synthetic aperture technique to a Sea Beam 2000 multi-beam echo sounder (Capell and Kiesel, 1989; Asada, 1992; Talukdar et al., 1992) in order to obtain high-resolution bathymetry. We verified the applicability of this technique by applying it to real data. While the synthetic aperture basically improves the alongtrack resolution by combining a number of elementary transmitting elements, the acrosstrack resolution was improved by using other techniques that will be described later. The synthetic aperture technique using the Sea Beam 2000 requires monitoring movements of the projector and hydrophone arrays with an accuracy of several centimeters. For this purpose the Kinematic GPS (Leick, 1995) and highaccuracy motion sensors were used. The horizontal position accuracy of the Kinematic GPS is estimated to be a few $\mathrm{cm}$.

Copy right (C) The Society of Geomagnetism and Earth, Planetary and Space Sciences (SGEPSS); The Seismological Society of Japan; The Volcanological Society of Japan; The Geodetic Society of Japan; The Japanese Society for Planetary Sciences.

\section{Application of Synthetic Aperture Technique to a Multi-Beam Echo Sounder}

The goal of this study is to detect seafloor crustal deformation by comparing repeated bathymetric measurements using a multi-beam echo sounder such as the Sea Beam 2000. The Sea Beam 2000 is a wide swath echo sounder used for seabed survey and is based on the cross-fan principle (USC and GS scientific and Technical Publications Group, 1966), with a transmitted fan beam and multiple received ones (Glen, 1970) - At $12 \mathrm{kHz}$ operating frequency, it provides 120 degrees of swath coverage to a depth of about $5,000 \mathrm{~m}$, and a 90 degree swath to a depth of $11,000 \mathrm{~m}$. The 120-degree swath employees 121 contiguous received beams with 2 degrees beamwidth in the athwartship. The projector array 4.3-meter length contains 28 projectors placed along the ship's keel. On the other hand, the receiver array contains 84 hydrophones. The hydrophones are placed athwartships in a V-shaped array on the keel with the hull angle of 10 degrees. Note that we can obtain a sufficient synthetic aperture effect by processing only a half of hydrophone array (42 hydrophones) data.

A synthetic aperture system requires monitoring the motion of its projector and hydrophone arrays with an accuracy of 1/8 of a wavelength (Cutrona, 1975). For the Sea Beam 2000 system whose wavelength is $12.5 \mathrm{~cm}$, an allowable error in monitoring the motion is $1.5 \mathrm{~cm}$. To achieve the highaccuracy positioning, we use the Kinematic GPS technique with the employment of dynamic motion sensors.

In this paper we describe the results of two synthetic aperture tests using the Sea Beam 2000 system installed on the survey vessels "Meiyo" and "Kaiyo" of the Japan Hydrographic Department.

\subsection{Fundamental of the method and the first sea test}

One measurement requirement is that the ship's heading is controlled so that the footprints of several (five in this study) contiguous fan beams have an overlap area (for the synthetic aperture technique). To obtain a sufficient overlap of transmitted beams the deflection of the ship's heading from a 


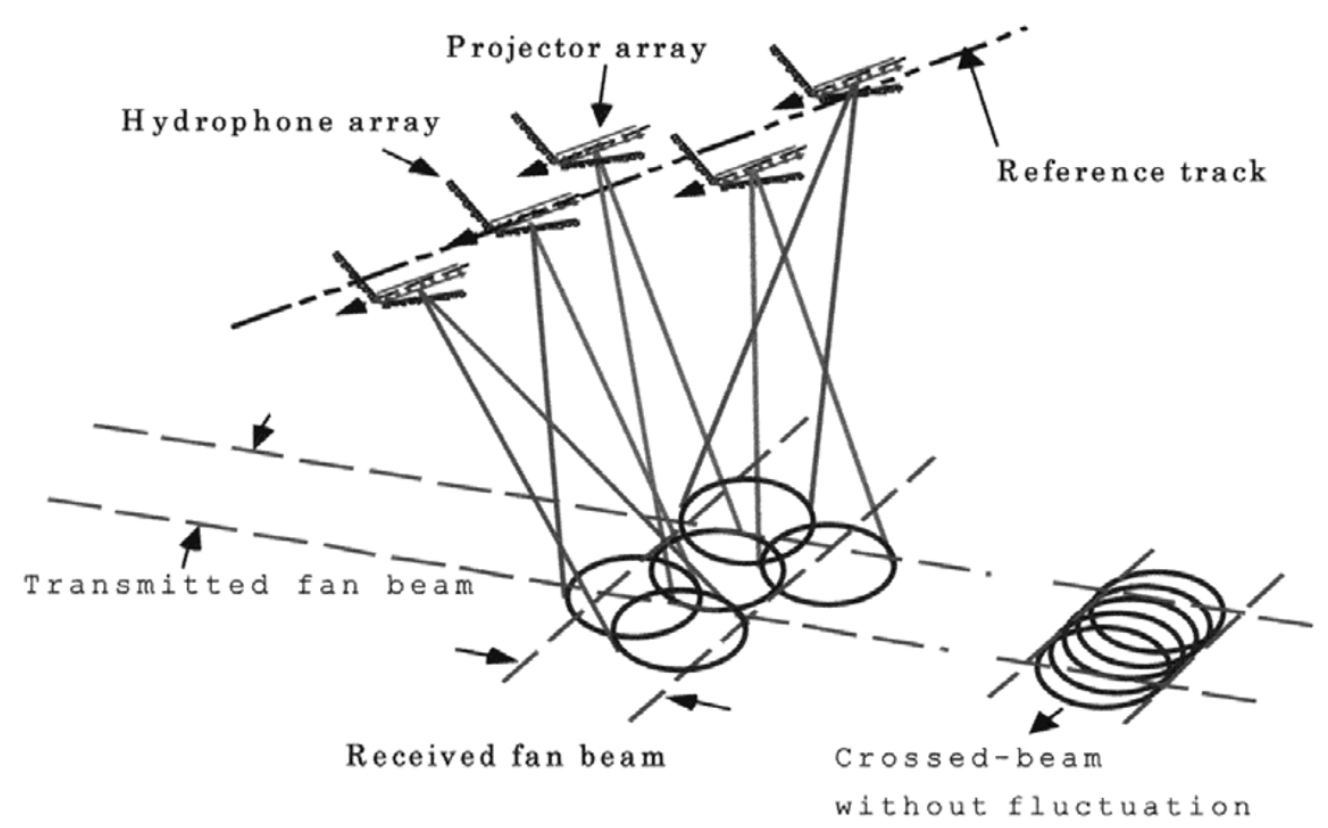

Fig. 1. Concept of applying a synthetic aperture technique to a multi-beam echo sounder. A transmitted fan beam is divided by multiple received fan beams. To form crossed-beams without fluctuation, the multiple received beams are compensated for deviations of the projector and hydrophone arrays from a reference track. Finally, the synthetic aperture process is applied to each crossed-beam.

straight line should be less than one degree for the period of five contiguous pings, although a small curve of the ship's course may be acceptable. We conducted the first sea test to confirm that this requirement was met. As a result, a good record of the motion was acquired although hydrophone signals had a low signal-to-noise $(\mathrm{S} / \mathrm{N})$ ratio. After deliberation, we were convinced that it was possible to apply the synthetic aperture technique to the Sea Beam 2000 multi-beam echo sounder as long as we could determine the position of its projector and hydrophone arrays with 1 centimeter accuracy.

We applied the synthetic aperture technique to the data from the first sea test. Figure 1 shows a concept of the synthetic aperture. After multiple received fan beams divide a transmitted fan beam (Asada and Ueki, 1998), the synthetic aperture process is applied to each divided-beam (that is crossed-beam). For forming crossed-beams without fluctuation, the multiple received beams are compensated for deviations of the projector and hydrophone arrays from a reference track. In this process, we typically set the synthetic aperture length to a travel distance for the period of five pings (about 25 seconds in the case of our sea test).

Figure 2 presents the method of beamforming without fluctuation. The deviations of the projector array and the hydrophone array from the reference track are compensated by memory-shifting and interpolating 42 hydrophone data. $\Delta t_{T}$ is the deviation in the time domain of the projector at the moment of transmission. $\Delta t_{R}$ is the deviation of the hydrophone array at each receiving time. $\Delta t_{i S}$ is the deviation of each hydrophone element which relates to the equipped angle and roll-angle. The position of the projector array on the reference track was beforehand calculated by the cubic polynomial interpolation. Finally, a SA beam was formed using five-ping received beams with no fluctuation from the reference track axis. The result of the first sea test satisfied us in the improvement of the resolution of the SA beams. An important factor for this improvement of resolution may be that the roll and pitch angles were small. Actually in the first sea test the sea state was so calm that they were both less than 0.5 degrees.

\subsection{High quality data obtained in the second sea test}

There were still improvements to be made after the first sea test, to measure detailed bathymetry with the multi-beam synthetic aperture. One was to increase the $\mathrm{S} / \mathrm{N}$ ratio of the hydrophone signals. Another was to improve the accuracy of motion monitoring system. Also, considering the goal of this study, we had to develop a positioning technique with a relative accuracy of $1.5 \mathrm{~cm}$ by combining Kinematic GPS positioning with a high-accuracy motion sensor on the sea several hundred km away from land.

To acquire the high quality hydrophone signals, preamplifiers were designed, hand-made and pretested. In addition two different types of the motion sensors, the HIPPY$120 \mathrm{C}$ (using the accelerometer and the pitch/roll pick-up coil) of the Sea Beam 2000 and a laser gyro JIMS-200R, were used. The Sea Beam 2000 hydrophone data with a fairly $\operatorname{good} \mathrm{S} / \mathrm{N}$ ratio were obtained during the second sea test in Sagami Bay in November 1997.

We also recorded the track of survey vessel using the Kinematic GPS in Sagami Bay under the simultaneously operation of two land reference stations: Cape Manazuru and Kasukabe, $10 \mathrm{~km}$ and $100 \mathrm{~km}$ away from the sea test area, respectively. Using these data we evaluated the accuracy of the Kinematic GPS positioning as described later. The vessel sailed three times with 2 or 3 knots along the survey line of 


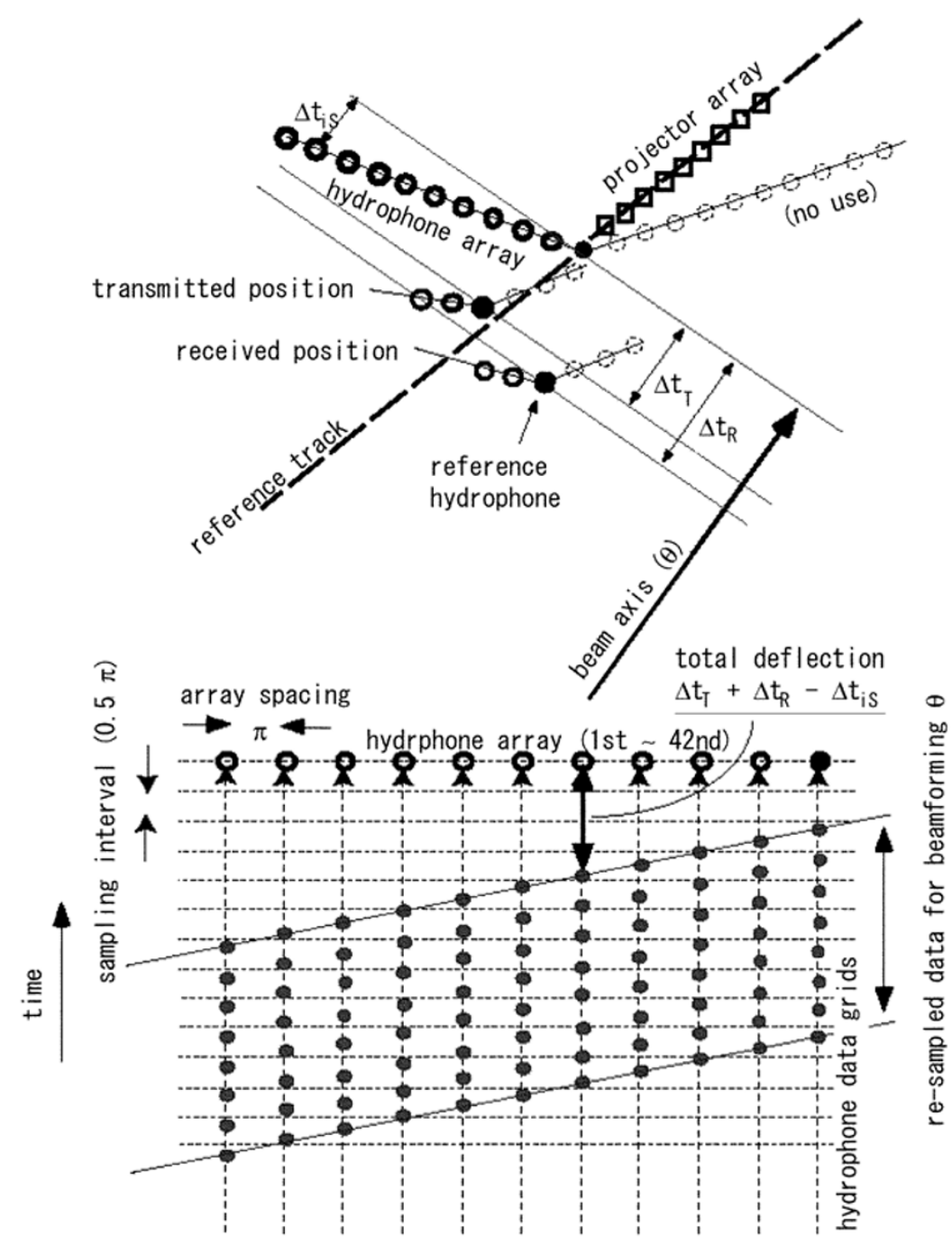

Fig. 2. Beamforming without fluctuation. (Upper) Deviations of a projector array and a half of hydrophone array from a reference track. (Lower) Memory-shifting and interpolating of hydrophone data in received beamforming without fluctuation. $\Delta t_{T}$ : Deviation in time domain of the projector at transmission. $\Delta t_{R}$ : Deviation of the hydrophone array at received time. $\Delta t_{i}$ : Deviation of each hydrophone element which depends on equipped angle and roll-angle.

$8 \mathrm{~km}$ length. During the sails, the steering wheel was fixed to keep the navigation lines as straight as possible.

In the second sea test, digital recording of the hydrophone signals had a good S/N ratio. Measurements with the Kinematic GPS and a motion sensor were also successfully done. The Kinematic GPS ensured an accuracy of a few $\mathrm{cm}$ for horizontal geodetic measurements. The motion sensor of the HIPPY-120C provided an accuracy of a few $\mathrm{cm}$ for the heave measurement and accuracy of 0.05 degrees for the rolling and pitching, and the JIMS-200R provided an accuracy of 0.05 degrees the yaw angle measurements.

We successfully kept a straight track sailing with fluctuations of less than one degree in the heading angle and a slow speed of $1.6 \mathrm{~m} / \mathrm{s}$. The ping interval of the Sea Beam 2000 was 5 seconds, thus the distance between the neighboring pings was $8 \mathrm{~m}$ in the tested sea area where water depth was to $900 \mathrm{~m}$. We recorded, with low noise through an analog- to-digital (A/D) conversion, signals of 42 hydrophones at the sampling frequency of $48 \mathrm{kHz}$. The high-cut filter of $20 \mathrm{kHz}$ was used in this $\mathrm{A} / \mathrm{D}$ conversion as an anti-aliasing filter. 14.5 giga-byte hydrophone data were recorded during one hour. Signals from 41 hydrophones showed good quality. One hydrophone malfunctioned.

\subsection{High-resolution bathymetry revealed by the syn- thetic aperture technique}

Based on the data collected at the sea tests, we developed the software for the synthetic aperture and topography analyses.

First, complex signals of the $12 \mathrm{kHz}$ component were prepared from the hydrophone signals with the use of 32 FFT samples. These signals had a frequency spectrum band of $1.5 \mathrm{kHz}$. However, the resolution was limited by the $250 \mathrm{~Hz}$ band pass filter used by the Sea Beam 2000 system. The recorded signals had such good quality that, if the signals 
with a broad frequency spectrum band of $1.5 \mathrm{kHz}$ had been processed, we could have acquired higher resolution bottom detection.

We produced 221 received beams with no fluctuation by synthesizing the 41 hydrophone's signals with the position data and the motion data. In this beam formation process, the center position of the projector at each ping was placed at the mean position of five pings. A data set encompassing the Kinematic GPS position, the pitching, the rolling, the heading and the heave was prepared in advance for the beam formation. Each hydrophone position was computed with a resolution of $1 \mathrm{~ms}$ using the motion data set. Corrections for the position fluctuation in the received beam formation were made through memory shifting and interpolation as explained in the previous section. Simultaneously, corrections for the projector deflection were made. Adjusting the reference point of the beams at the center of the five pings, we produced 221 received beam signals. Figure 3 shows (a) the 221 received beam signals at 0.5 degrees interval in the swath width between -55 and 55 , (b) seabottom detection in the beam signals and its gates setting, and (c) sampled signals around the seabottom for the synthetic aperture process. The good quality beam signals were acquired by using the hand made pre-amplifiers and by the correction of position fluctuation. In the seabottom detection of Fig. 3(b), only a time-sliced beam pattern (signals) with a high $\mathrm{S} / \mathrm{N}$ ratio is judged as a high-quality seabottom echo, and a peak point of the time-sliced beam signals provides a direction of the timesliced seabottom echo (Talukdar et al., 1992). A time-sliced beam pattern means a cross section of multi-beam signals at a particular travel time in Fig. 3(a).

The horizontal positioning accuracy of the projector is estimated to be a few $\mathrm{cm}$ by taking account of the accuracy of the Kinematic GPS (presented in the next section), the accuracy of the motion sensor, and the locations of the projector, the hydrophone, the GPS antenna and the HIPPY motion sensor on the ship. The GPS antenna was installed $17 \mathrm{~m}$ above, $4 \mathrm{~m}$ fore and $3.7 \mathrm{~m}$ right the projector array. The HIPPY motion sensor was installed $3.3 \mathrm{~m}$ directly above the projector array. On the other hand, the maximum vertical position error is estimated to be about $10 \mathrm{~cm}$, by comparing two heave estimations at the projector position located from the GPS antenna and the HIPPY motion sensor. Hence, the total accuracy of the corrections for the motion of the projector and hydrophone array is approximately 1 wavelength (12.5 $\mathrm{cm})$. To suppress the large position errors, we developed an automatic adjustment software. This software provided a better synthetic aperture effect. Five pings of the sampled seabottom signals were synthesized by a maximized correlation method with a time-sliced beam pattern of amplitude and phase. In the time-sliced beam pattern, one degree shifting of off-nadir angle is expected to generate phase changes between 38 and 67 degrees. Correlation values of the timesliced beam signals among the five pings were calculated by phase shifting between -180 and 180 degrees searching the best fit point. The time-sliced signals are independently processed for each side of port and starboard, and an echo from a seabottom point was assumed to generate a timesliced beam pattern. In conclusion, by synthesizing the 5 pings by 221 beams, we succeeded in obtaining an aperture

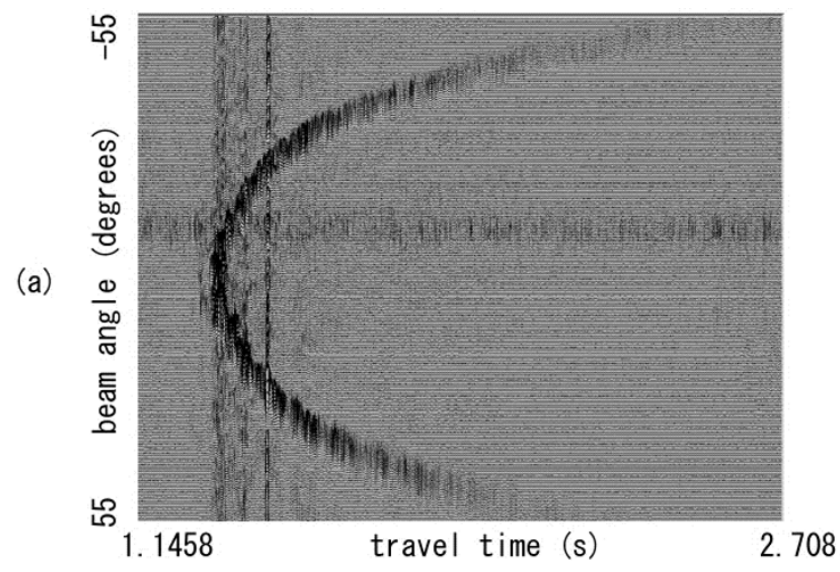

(b)

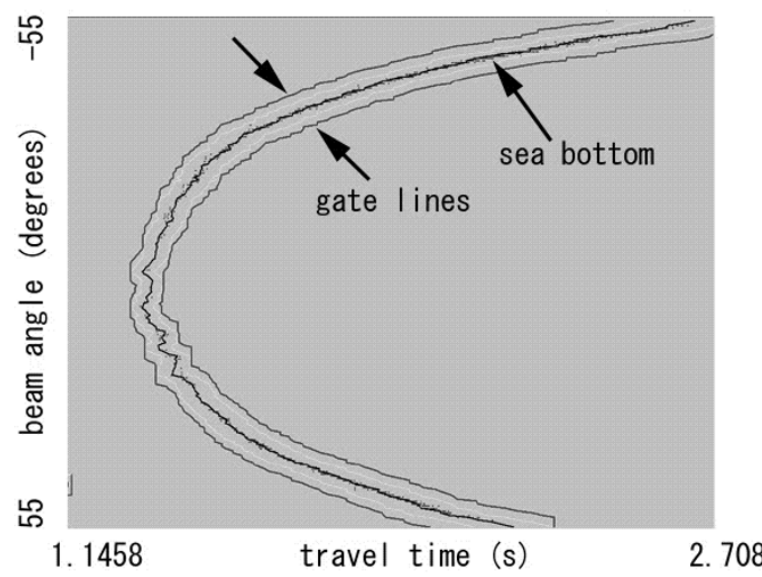

(c)

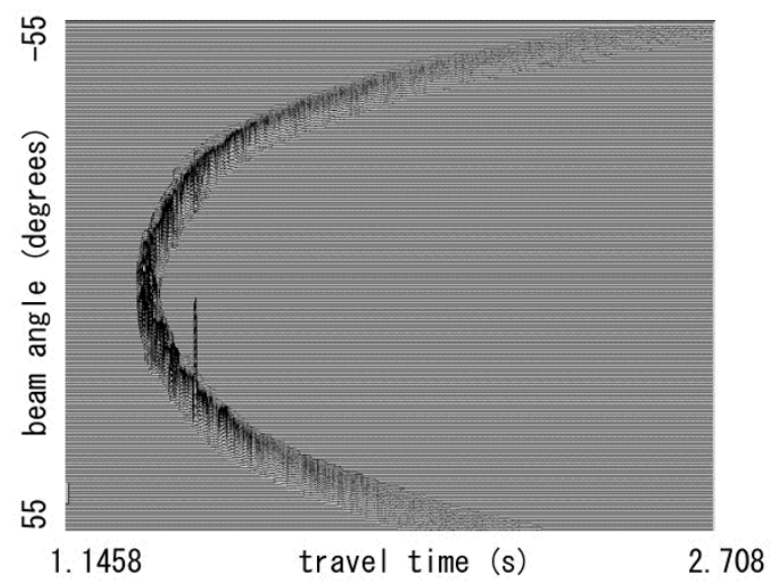

Fig. 3. (a) 221 received beams between -55 and 55 degrees without fluctuation, (b) seabottom detection and gates setting, and (c) sampled seabottom areas for the synthetic aperture process. Five pings of the sampled seabottom signals were synthesized by a maximized correlation method with a time-sliced beam pattern.

length of 8 times the original projector. The transmission fan beamwidth was improved from 2 degrees to 0.3 degrees.

Finally, we obtained high-resolution bathymetry in Fig. 4(b) from the multi-beams through the synthetic aperture processing. Because the $\mathrm{S} / \mathrm{N}$ ratio of the multi-beam signals was also significantly improved by the synthetic aperture effect, wider swath and higher resolution bathymetry than the normal Sea Beam 2000 in Fig. 4(a) were achieved. More 


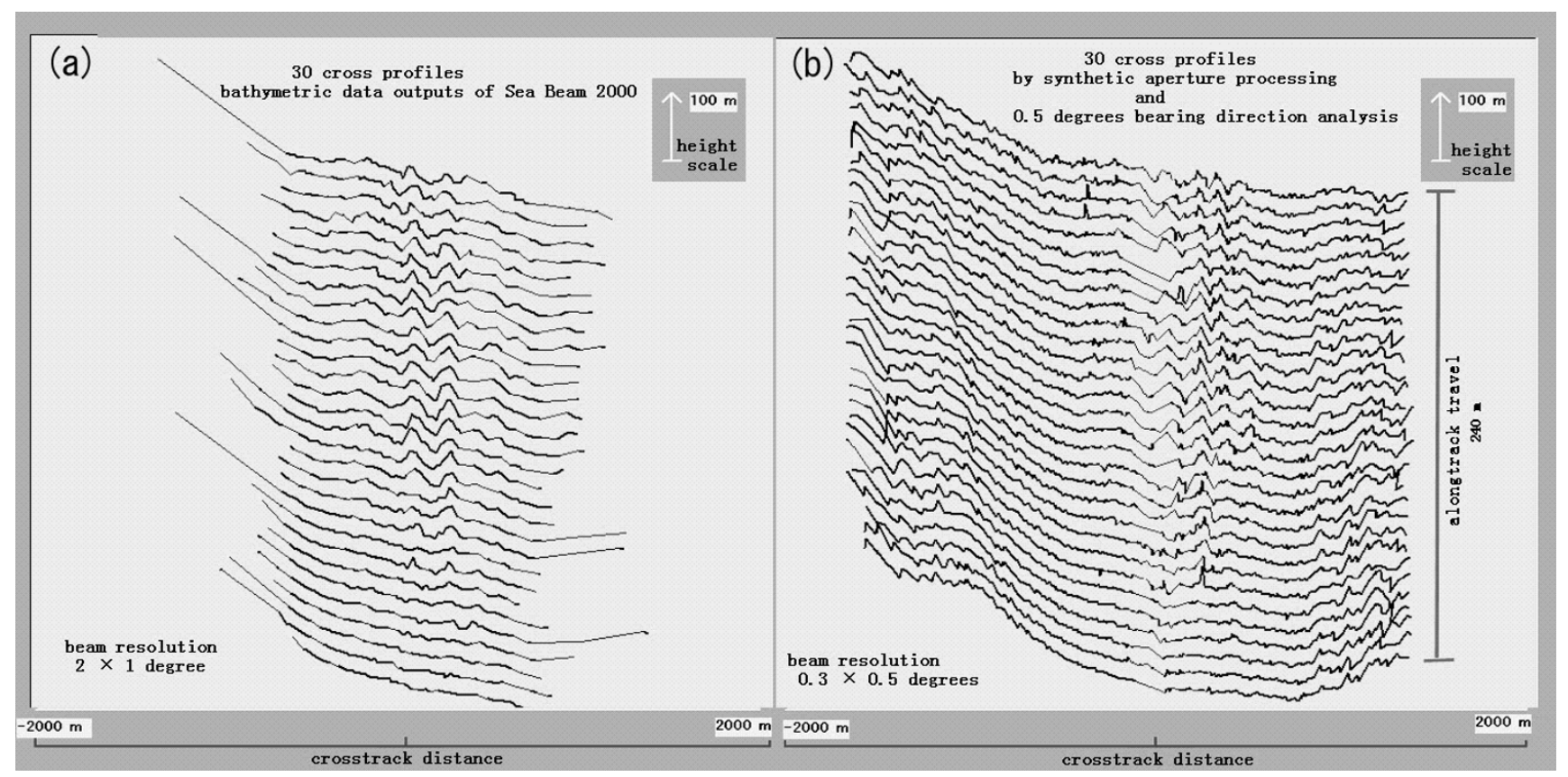

Fig. 4. Sea Beam 2000 bathymetry profiles before (a) and after (b) synthetic aperture processing. Vertical depth is about $900 \mathrm{~m}$, the survey site is $10 \mathrm{~km}$ eastern off Manazuru cape in Sagami Bay. More detailed topographical features, such as small gullies and terraces, appears in (b).

detailed topographical features, such as small gullies and terraces, have been detected. However, the lack of bathymetry data was shown in the vertical portions, between crosstrack distances of -200 and $200 \mathrm{~m}$, in Fig. 4(b). The vertical portions were unfavorable for measuring an athwartship direction with 0.5 degrees high resolution from seabottom multibeam signals, compared with the normal Sea Beam 2000 measurement with 2 degrees resolution.

Because $48 \mathrm{kHz}$ sampling signals of the hydrophones are recorded, the highest time-resolution of $1 / 48 \mathrm{~ms}$ provided a range resolution of $3 \mathrm{~cm}$. However, considering that received beams were produced with the fluctuation components suppressed to the accuracy of approximately 1 wavelength, repeated bathymetry measurement may detect subsea crustal motion with about $12.5 \mathrm{~cm}$ accuracy.

\subsection{Evaluation of long baseline Kinematic GPS}

As mentioned in the introduction, our target is to survey the sea area several hundred $\mathrm{km}$ away from a land. One primary objective of the second sea test was to evaluate the accuracy of Kinematic GPS positioning with the baseline distance of about $100 \mathrm{~km}$ from a reference fixed point on land. For the evaluation, we compared the estimated sailing tracks from two reference stations, which were located at Manazuru with a short baseline of about $10 \mathrm{~km}$ and at Kasukabe with a long baseline of about $100 \mathrm{~km}$ (see Fig. 5).

All the GPS data were collected through Trimble 4000SSE dual frequency receivers with eighteen tracking channels. The GPS carrier phase measurements were recorded with the 1 second or 0.5 seconds sampling rate during the sailing along eight survey lines. By combining the data of reference stations, the sailing tracks of "KAIYO" were estimated using the post-processing software "GPSurvey" by Trimble
Navigation Limited. In the processing, we used two reference stations independently to produce two estimates of the position at each time.

Figure 5 illustrates the differences between two estimated sailing tracks for a survey line. Of course, these differences stemmed from the errors in the position estimations. We can find the offsets of a few $\mathrm{cm}$ in both latitude and longitude directions. With respect to the temporal changes, we find the overlap of high frequency scatters and low frequency variations, the period of which was typically about 10 minutes. The high frequency scatters were usually less than $1 \mathrm{~cm}$ in amplitude, while the low frequency variations $1-3 \mathrm{~cm}$. The variations with the same amplitude level were found in the results for the other survey lines. On the other hand, the offset values were different among three survey lines. This suggests that the main source of the offsets was not the errors in the coordinates of reference points. We speculate that they were mainly caused by the inaccuracy of integer phase ambiguity resolution in the Kinematic GPS processing. In conclusion, we consider that the Kinematic GPS positioning with the baseline of $100 \mathrm{~km}$ is accomplished with the accuracy of a few cm level in the horizontal components.

On the other hand, the difference in the vertical component has an offset of around $15 \mathrm{~cm}$ and low frequency variations at a $3.5 \mathrm{~cm}$ level, both larger than those of the horizontal component. Reviewing through the whole results of eight survey lines, we found the similar amplitudes of variations, while the values of offsets were not uniform. These features were similar to the horizontal components. However, taking into account that the present solar activity has come close to its minimum and that the meteorological condition was exceptionally stable during our observation, our trial might be 
(a) Lat itude

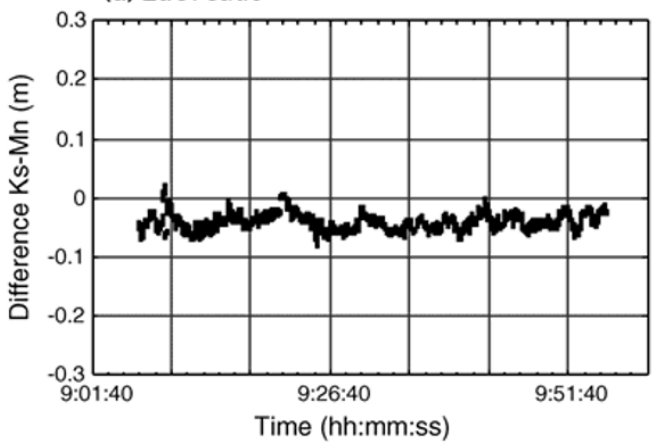

(b) Long i tude

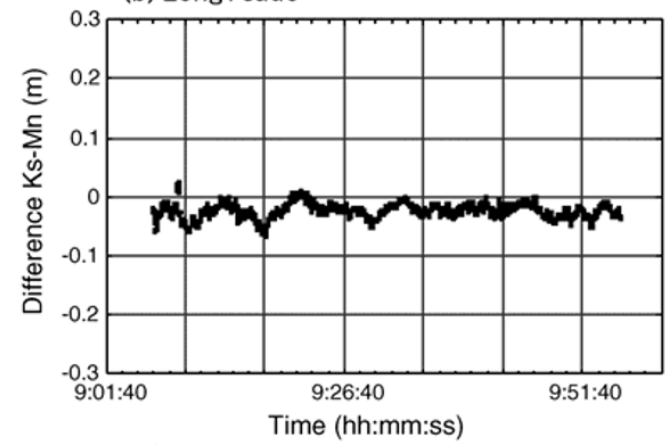

(c) Height

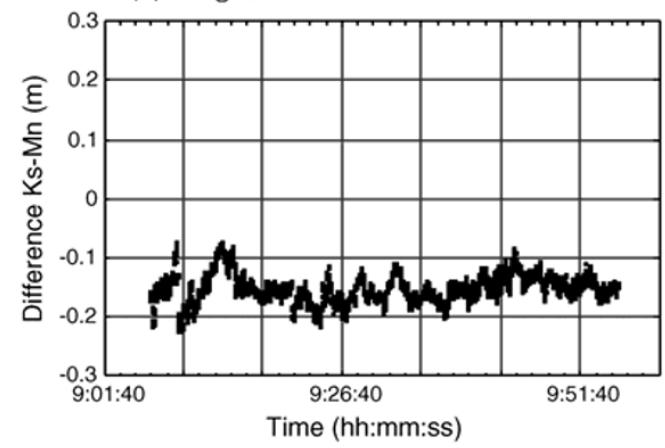

Fig. 5. Position differences of the survey vessel "Kaiyo" determined by using Kinematic GPS positioning with reference stations at Manazuru and Kasukabe (1997.10.25).

an unusual case conducted under a very favorable condition. It is necessary to test the performance of the Kinematic GPS positioning under less favorable meteorological and solar activity conditions in future.

\section{Conclusion}

The synthetic aperture technique has been demonstrated to be a useful tool in the multi-beam measurement of the ocean bottom topography. Given the present positioning accuracy of the Kinematic GPS, the SA technique can be applied to areas very far $(\sim 100 \mathrm{~km})$, off shore. For example, seafloor motion along the Nankai trough plate boundary can be studied using this technique. It has been shown that the synthetic aperture is effective even if the vertical positioning accuracy lies in the order of $10 \mathrm{~cm}$.

Acknowledgments. Authors would like to thank the captains and crews of the survey vessels "Meiyo" and "Kaiyo" for cooperation, and Dr. M. Fujita for cooperation in Kinematic GPS positioning. We are also grateful to Professor F. N. Spiess and Professor H. Fujimoto a lot of helpful comments. This study is carried out under the project of Japan Science and Technology Agency.

\section{References}

Asada, A., Sea Beam 2000: Bathymetric surveying with interferometry, Sea Technology, 33(6), 10-15, 1992.

Asada, A. and T. Ueki, Synthetic aperture analysis using a multibeam echo sounder, J. Acoust. Soc. Jp., (E), 19(4), 259-268, 1998.

Capell, W. J. and K. C. Kiesel, An extend capability multibeam bathymetric mapping system, IEEE Conf. Proceedings of OCEANS' 89, 1124-1136, 1989.

Cutrona, L. J., A comparison of sonar system performance achievable using synthetic aperture techniques, J. Acoust. Soc. Am., 58(2), 336-348, 1975.

Glen, M., Introducing an operational multi-beam array sonare, International hydrographic Review, XLVII(1), 35-39, 1970.

Leick, A., GPS Satellite Surveying, 2nd ed., Chap. 10, pp. 380-381, John Wiley \& Sons, New York, 1995.

Massonnet, D., M. Rossi, C. Carmona, F. Adragna, G. Peltzer, K. Feigl, and T. Rabaute, The displacement field of the Landers earthquake mapped by radar interferometry, Nature, 364, 138-142, 1993.

Spiess, F. N. and V. C. Anderson, Wide swath precision echo sounder, U. S. Patent, 4, 400, 803, 1983.

Stubbs, A. R., B. S. McCartney, and J. G. Legg, A method of wide swath depth measurement, International hydrographic Review, LI(1), 23-59, 1974.

Talukdar, K., W. Capell, and C. Zabounidis, Sidescan survey results from a multibeam sonar system-SEA BEAM 2000, Marine Geodesy, 15, 63-79, 1992.

USC and GS scientific and Technical Publications Group, Narrow beam transducer sounding system yields excellent results in operation aboard U.S.C. and G.S. ship Surveyor, International hydrographic Review, XLIII(1), 37-42, 1966.

A. Asada (e-mail: asada@iiis.u-tokyo.ac.jp) and T. Yabuki (e-mail: tyabuki@cue.jhd.go.jp) 